\title{
MOTIVAÇÃO DE NOMEAÇÃO DOS HIDRÔNIMOS SINOPENSES MOTIVATION OF THE SINOPENSES HYDRONYMS NOMINATION
}

\author{
Marieta Prata de Lima DIAS \\ Universidade Federal do Mato Grosso (UFMT) \\ Campus Universitário de Sinop \\ marietaprataldias@gmail.com
}

\begin{abstract}
Resumo. A nomeação da riqueza hídrica do município de Sinop (MT) justifica o interesse desta pesquisa. Com base nas cartas topográficas atuais e com apoio teórico da Toponímia e da Linguística Cognitiva, buscou-se apreender o processo de interação social e valores culturais marcados neste ato denominativo. Não há atenção à dimensão humana de conceptualização, sem preocupação com o processo de cognição, formação do conceito e nomeação; é como se o conceito existisse antes mesmo de ser designado por um termo. Os hidrônimos foram classificados física e antropologicamente visando à percepção da motivação do homem denominador, seguindo as classificações toponímicas propostas por Dick. Observou-se não ser tão numerosa a tipologia dos acidentes (córrego, ribeirão, cabeceira, rio, lagoa e cachoeira) em comparação à riqueza taxionômica dos sessenta e cinco hidrônimos. Também a significativa presença de antropônimos femininos desvela 0 modelo metafórico-conceptual de que a riqueza da natureza hídrica amazônica, abstrata e "mágica", é concretizada em um domínio próximo e familiar - a sublime abundância da bondade feminina.
\end{abstract}

Palavras-chave: Toponímia; hidrônimo; Sinop.

Abstract. The nomination of the hydrographic richness of the municipality of Sinop (MT) justifies the interest of this research. Based on current topographic charts and with theoretical support from Toponymy and Cognitive Linguistics, we sought to understand the process of social interaction and cultural values marked in this denominational act. There is no attention to the human dimension of conceptualization, without concern for the process of cognition, concept formation and appointment; it is as if the concept existed before it was even designated by a term. The hydronyms were classified physically and anthropologically aiming at the perception of the motivation of the denominator, following the toponymic classifications proposed by Dick. It was observed that the typology of the accidents (creek, stream, headwater, river, lagoon and waterfall) was not so numerous as the taxonomic richness of the sixty-five hydrographies. Also the significant presence of female anthropomorphs reveals the metaphorical-conceptual model that the wealth of Amazonian, abstract, and "magical" water-nature is embodied in a familiar and familiar domain - the sublime abundance of feminine goodness.

Keywords: Toponymy; hydronimide; Sinop.

\section{Introdução}

O município de Sinop é localizado no centro-norte do Estado de Mato Grosso (Brasil), tem 398 mil hectares de extensão e fica situado na área do 
zoneamento ecológico-econômico da Amazônia, denominada Fronteira Agroflorestal e Pecuária. 0 fazer denominativo da riqueza hídrica da bacia amazônica justifica foi alvo de interesse por esta pesquisa, que teve dois objetivos: a) classificar os hidrônimos do município de Sinop, conforme a classificação proposta por Dick; e b) buscar apreender o processo de interação sociocognitiva marcado no ato denominativo.

Essa busca da compreensão do mecanismo intelectual que possibilita tornar nome a palavra-sígnica é tratada pela Onomástica, ciência maior que trata do acervo lexical de um povo, incluindo uma análise mais completa que simplesmente nomes, uma linguagem de especialidade diferenciada, não técnica. Nela estão inclusas a Antroponímia e a Toponímia, cujo objeto é a relação entre o estudo do espaço (natureza geográfica, fontes documentais) e seu nome. Se considerarmos que os topônimos da linguagem nativa sejam considerados os substratos, os quais em algum momento conviveram com os topônimos de etnias e falares diversos constituindo os topônimos adstratos, pode-se dizer que, nas cartas topográficas atuais constam os superstratos toponímicos, ou seja, os topônimos de um período civilizatório, organizado política e geograficamente.

\section{Diálogo com pesquisadores}

A Linguística Cognitiva (LC), iniciada no final da década de 70 por Eleanor Rosch, seguida por George Lakoff e Lakoff \& Johnson, entre outros (SILVA, 2018), não considera a linguagem humana como sistema autônomo, mas como instrumento de organização, processamento e transmissão de informação semântico-pragmática. 0 significado é concebido "como construção mental, em movimento contínuo de categorização e recategorização do mundo a partir da interação de estruturas cognitivas e modelos compartilhados de crenças socioculturais" (FERRARI, 2011, pág. 15.). A significação e a estrutura linguística dependem de determinadas estruturas do conhecimento (individualmente idealizado e interindividualmente partilhado) sobre o domínio da experiência. A LC também atribui grande importância aos processos de metáfora e metonímia. No processo de produção metafórica, relacionam-se dois domínios conceptuais (por exemplo, em "Ela foi recebida calorosamente na festa", afeto X temperatura), com base em uma estrutura de conhecimento presente na memória de longo prazo. 
A Toponímia foi instituída como disciplina na França, em 1878, por Auguste Longnon; vários estudiosos se dedicaram à essa ciência, tais como Albert Dauzat, Teodoro Sampaio, Armando Levy Cardoso, Carlos Drumond, Maria Vicentina de Paula do Amaral Dick, entre outros pesquisadores (SILVA e SILVA, 2016).

Dick esclarece como os topônimos surgem:

Topônimos que descrevem o meio surgem de algumas formas: a princípio, com autoria, como formas expressivas de um discurso, são substantivos comuns que se referem a um aspecto do acidente (o rio que é grande; as águas turvas da lagoa). Na sequência, há dois caminhos: repetidas, formalizam-se em nome próprio e dessacralizam a autoria, simplificam-se e priorizam os índices (rio Grande; água Turva) ou toponimiza-se também o primeiro elemento (Rio Grande passa a ser município, e Água Turva da Lagoa, bairro, por exemplo). (DICK, 2006, p. 96)

Carvalho aborda os aspectos envolvidos no ato de nomear:

A ação de nomear ou denominar lugares estabelece relações que denotam aspectos variados das atividades humanas: sociais, políticos, religiosos, culturais, regionais, econômicos, entre outros. Esses aspectos podem apresentar-se com características regionais, mais específicas ou gerais. É certo também que algumas delas são mais produtivas em acidentes físicos que em acidentes antrópicos, mas em geral, isso não constitui regra; podem apresentar-se, diferentemente, em um ou em outro nível, e pode-se até mesmo, observar que são variáveis de acordo com as especificidades das regiões.

Genericamente, os topônimos dos acidentes físicos são mais estáveis e mais espontâneos do que os antrópicos e representam mais o aspecto de anonimato do denominador. Esses fatores, às vezes, apresentam-se como obstáculos às classificações taxionômicas, porque de certa forma contribuem para a opacidade dos topônimos, ou seja, dificultam a recuperação do significado dos topônimos. (CARVALHO, 2010, p. 22).

Considerando com Dick (1980, pág. 24) que "a motivação toponímica pode ser encarada sob dois pontos de vista: aquele do denominador e o da natureza do produto dessa escolha, isto é, da substância mesma do topônimo, revelada pelos componentes linguísticos", ousamos classificá-los conforme nos apresentam e buscar auxílio na Linguística Cognitiva para novamente ousar entender o processo psicológico da preferência por este ou aquele tipo. Trata-se, contudo, de um processo semasiológico pois parte-se do NOME para a INTENÇÃO, como bem afirma Dick (1980, citando DICK, 1975, p. 376)

Esse amálgama intricado de nomes, que constitui a tessitura toponomástica propriamente dita de um território, deve sofrer, por sua vez, um ordenação ou catalogação a partir, agora, não do doador (o homem) e, sim, do produto gerado. Num primeiro momento é, pois, o homem quem preside a escolha do nome, permitindo a averiguação de todos os impulsos que sujeitaram o ato nomeador; num segundo 
momento, é a denominação que irá condicionar e determinar os rumos dos estudos toponímicos.

Para a Linguística Cognitiva, a significação e a estrutura linguística dependem de determinadas estruturas do conhecimento sobre o domínio da experiência, ou seja, os processos cognitivos são delimitados pela experiência e estruturados pelo corpo. Por exemplo, sobre a percepção de cor, o ser humano tem três tipos de fotorreceptores, enquanto esquilos e coelhos possuem dois e pombos, quatro; também não enxergamos no escuro, diferentemente de cascavéis que o fazem por perceberem o calor emitido por outros organismos. Isso diferencia nossa experiência, determinando a natureza e amplitude nesse ato.

O significado é uma construção mental, de contínuo categorizar e recategorizar o mundo pela interação entre estruturas cognitivas e modelos de crenças socioculturais. Trata-se de um conhecimento individualmente idealizado e interindividualmente partilhado. No ato de categorizar, envolvemos protótipos ou elementos similares relacionados ao contexto sociocultural.

Silva (1997) exemplifica a abrangência presente em categorias, ilustrando com exemplares que se encaixam na categoria "ave":

Já bird (em português, ave mas também pássaro), embora apresente exemplares mais representativos do que outros (cf. o pardal ou o tordo face ao pinguim ou à avestruz) e o agrupamento dos seus elementos se faça por similaridades parciais e não por propriedades comuns (traços como 'capacidade de voar', 'com penas', 'com asas' não são comuns a todas as espécies, já que o pinguim e a avestruz não podem voar, o pinguim não tem penas perceptíveis, etc.), é uma categoria extensionalmente discreta (falantes suficientemente informados sabem que o morcego não é uma ave e que o pinguim, apesar de tudo, o é); o que mostra que grau de pertença a uma categoria e grau de representatividade não se implicam necessariamente. (SILVA, 1997, p. 8).

A classificação criada por DICK (980) e reorganizada por Carvalho (2010) abaixo serviu como modelo para categorizar os hidrônimos sinopenses:

\section{Natureza física:}

- Astrotopônimo $\Rightarrow$ corpos celestes em geral. Ex.: Serra da Estrela (MT).

- Cardinotopônimos $\Rightarrow$ posições geográficas. Ex.: Córrego do Meio (MT).

- Cromotopônimos $\Rightarrow$ escala de cores. Ex.: Morro Azul (MT).

- Dimensiotopônimos $\Rightarrow$ características dimensionais dos acidentes geográficos. Ex.: Córrego Fundo (MT). 
- Fitotopônimo $\Rightarrow$ índole vegetal. Ex.: Serra da Guariroba (G0).

- Geomorfotopônimo $\Rightarrow$ formas topográficas (como serra, elevação, ilha). Ex.:

Córrego Chapada (MT).

- Hidrotopônimo $\Rightarrow$ nome de acidentes hídricos. Ex.: Córrego do Açude (GO).

- Igneotopônimo $\Rightarrow$ fogo e os produtos de sua ação. Ex.: Cachoeira da Fumaça (MT).

- Litotopônimo $\Rightarrow$ índole mineral e da constituição do solo. Ex.: Ribeirão Areia (GO).

- Meteorotopônimo $\Rightarrow$ fenômenos atmosféricos. Ex.: Serra do Vento (PB).

- Morfotopônimo $\Rightarrow$ forma geométrica. Ex.: Morro Redondo (MT).

- Zootopônimo $\Rightarrow$ índole animal. Ex.: Córrego das Éguas (GO).

\section{Natureza antropocultural}

- Animotopônimo $\rightarrow$ vida psíquica e espiritual. Ex.: Córrego Boa Vista (GO).

- Antrotopônimo $\rightarrow$ nomes próprios individuais, hipocorístico, apelido. Ex.: Barbosa (SP).

- Axiotopônimo $\rightarrow$ títulos e dignidades + nome próprio. Ex.: Coronel Ezequiel (RN).

- Corotopônimo $\rightarrow$ coro (=região, país) nomes de cidades, países, estados, regiões e continentes. Ex.: Seringal Quixadá (AC).

- Cronotopônimo $\rightarrow$ indicadores cronológicos Ex.: Nova Aurora (G0).

- Dirrematotopônimo $\rightarrow$ (dirrema: frase que contém dois núcleos - tema (o cão) + rema (ladra) - topônimos compostos por frases ou enunciados linguísticos. Ex.: cidade ou bairro Valha-me Deus (MA) e córrego Rola Burro (MT).

- Ecotopônimo (eco gr: casa, casebre, ambiente) $\rightarrow$ habitações de modo geral. Ex.: Chalé (MG).

- Ergotopônimo (ergo: $g r$ trabalho) $\rightarrow$ relativos a elementos da cultura material. Ex.: Jangada (MT).

- Etnotopônimo $\rightarrow$ elementos étnicos. Ex.:Capixaba (AC).

- Hierotopônimo (hiero: sagrado) $\rightarrow$ nomes sagrados de qualquer crença. Ex.: Capela (AL).

- Hagiotopônimo (hagio: santo/a) $\rightarrow$ nomes sagrados do repertório romano. Ex.: Santa Luzia (BA).

- Mitotopônimo $\rightarrow$ entidades mitológicas. Ex.: Exu (PE).

- Historiotopônimo $\rightarrow$ movimentos de cunho histórico-social e seus representantes. Ex.: Plácido de Castro (AC).

- Hodotopônimo $\rightarrow$ (hodo: caminho) - relativo às vias de comunicação rural ou urbana. Ex.: Ponte Allta (SC).

- Numerotopônimo $\rightarrow$ relativo aos numerais. Ex.: Dois Vizinhos (PR). 
- Poliotopônimo $\rightarrow$ relativo à aldeia, vila, cidade etc. Ex.: Vila Nova do Mamoré (RO).

- Sociotopônimo $\rightarrow$ relativo às atividades profissionais, locais de trabalho e locais de encontro comunitário. Ex.: Pracinha (SP).

- Somatopônimo (soma: corpo) $\rightarrow$ relativo às partes do corpo humano ou animal. Ex.: Braço do Trombudo (SC).

\section{Dados coletados e classificados}

\section{Dick diferencia hidrônimo:}

"nomes de acidentes hidrográficos em geral, não importando a natureza linguística do objeto nomeado, e evidenciado pela denominação, se humano ou não humano, animado ou inanimado, nem a natureza dos campos semânticos envolvidos" (DICK, 2004, p. 126-137)

de hidrotopônimo:

"acidentes geográficos em que, na denominação toponímica, o elemento hidronímico está presente, seja o termo genérico água ou as designações de cursos d'água específicos como córrego, rio, ribeirão, etc.: serra das Águas (GO) e Âgua Boa (MG)" (DICK, 2004, p. 126-137).

Como dito anteriormente, considera-se que nas cartas topográficas atuais constam os superstratos toponímicos, ou seja, os topônimos de um período civilizatório, organizado política e geograficamente, com apoio teórico da Toponímia e da Linguística Cognitiva buscou-se apreender o processo de interação social e valores culturais marcados neste ato denominativo, por entender que os termos toponímicos são aqui estudados sincronicamente. Não há atenção à dimensão humana de conceptualização, sem preocupação com o processo de cognição, e formação do conceito e nomeação; é como se o conceito existisse antes mesmo de ser designado por um termo.

Constantes no discurso especializado das cartas topográficas oficiais do município, nelas organizados na lógica geográfica, topônimos como Córrego Limpador, Córrego Nádia, Córrego Úrsula, Ribeirão Selma, Rio Teles Pires, Cachoeira do Suplício, entre outros, foram classificados física e antropologicamente visando à percepção da motivação do homem denominador, seguindo as classificações toponímicas propostas por Dick. Vale lembrar que o nomeador é visto como anônimo representante do contexto/ação/tempo pois, ao se tornar nome próprio, o topônimo fica dessacralizado de autoria.

Os 66 hidrônimos são assim categorizados: 
A) - De natureza física (17):

Dois (2) cardiotopônimos: Córrego Norte e Córrego do Meio; 2 cromotopônimos: Rio Azul e Ribeirão Preto; (2) dimensiotopônimos: Córrego Fundo e Córrego Raso; (1) geomorfotopônimo: Lagoa da Várzea; (3) hidrotopônimo: Córrego da Corredeira, Córrego Lagoa Morta e Cabeceiras do Ribeirão Selma; (3) litotopônimos: Ribeirão Petronilha, Ribeirão Petrolina e Cristalino; (1) morfotopônimo: Ribeirão Baixada Morena; (3) zootopônimos: Córrego das Borboletas, Córrego da Porquinha Seca e Ribeirão Quero-Quero.

B) - De natureza antropocultural (46):

Trinta e dois (32) antropônimos: Córrego Abgair, Córrego Anice, Córrego Circe, Córrego Doriana, Córrego Erna, Córrego Guacira, Córrego Guilhermina, Córrego Ieda, Córrego Isaura Egle, Córrego Joselita, Córrego Lola, Córrego Márcia, Córrego Maria, Córrego Nádia, Córrego Nalva, Córrego Nilsa, Córrego Rose, Córrego Rossana, Córrego Simone, Córrego Úrsula, Córrego Valéria, Cabeceiras do Ribeirão Selma, Ribeirão Araciaba, Ribeirão Guacira, Ribeirão Helena, Ribeirão Mafalda, Ribeirão Neusa, Ribeirão Selma, Rio Roquete e Rio Teles Pires. (1) axiotopônimo: Córrego Condessa. (1) dirrematotopônimo: Ilha Sem-Nome. (1) ergotopônimo: Córrego Caldeirão. (3) etnotopônimos: Córrego do Bugre, Cachoeira dos Índios e Rio Caiabi. (1) hierotopônimo do tipo mitotopônimo: Cachoeira Curupi. (1) historiotopônimo: Cachoeira Treze de Maio. (1) poliotopônimo: Córrego da Ilha. (3) sociotopônimos: Córrego do Suplício, Cachoeira do Suplício e Córrego Limpador. (2) somatopônimos: Lagoa Morta e Ribeirão Velho. (3) topônimos não se inseriram em nenhuma classificação: Cachoeira Aquili, Córrego Cisneiros e Córrego Atneia.

A nomeação com base na natureza física é distribuída de forma mais harmoniosa, sendo que os hidrotopônimos e litotopônimos foram mais numerosos que os outros. Em outras palavras, nos hidrotopônimos - originados de acidentes hidrográficos - a riqueza hídrica foi repetida na nomeação de outro acidente hídrico; nos litotopônimos, a presença mental de pedra e cristal evidenciaram-se. 0 nomeador, no contexto da Amazônia, repassou em palavras sua vivência experiencial relativa à abundância de água e minerais da paisagem.

Na nomeação de natureza antropocultural, a quantidade de antrotopônimos é significativamente maior que todas outras categorias. No conjunto das "outras 
categorias", etnotopônimos e sociotopônimos aparecem em segundo grau de frequência (com 3 nomes cada), seguidos de somatopônimos (com 2 nomes) e as outras categorias ficaram representadas por apenas um topônimo cada axiotopônimos, dirrematotopônimo, ergotopônimo, hierotopônimo (e aqui é importante observar que não foi hagiotopônimo mas um mitotopônimo característico da mata (Cachoeira Curupi), historiotopônimo e poliotopônimo.

Dentre os 32 antropônimos, 30 são nomes femininos. Nomes de mulheres foram os mais relacionados à riqueza hídrica da região. Na sequência, mas com grande diferença quantitativa, aparecem os elementos étnicos e as atividades profissionais e movimentos de cunho histórico-social (por sinal, nada muito feliz Córrego do Suplício e Cachoeira do Suplício). Não constaram nomes relativos à vida psíquica e espiritual, a nomes de cidades, países, estados, regiões e continentes e a indicadores cronológicos. "O significado não é uma coisa; ele envolve o que é significativo para nós. Nada é significativo em si mesmo. A significatividade deriva da experiência da atuação como um ser de um certo tipo em um ambiente de um certo tipo" (Lakoff, 1987, p. 292).

\section{Visualização para reflexão}

Os gráficos permitem visualizar o todo de uma forma mais global, facilitando a reflexão sobre os dados.

\section{NATUREZA FÍSICA}

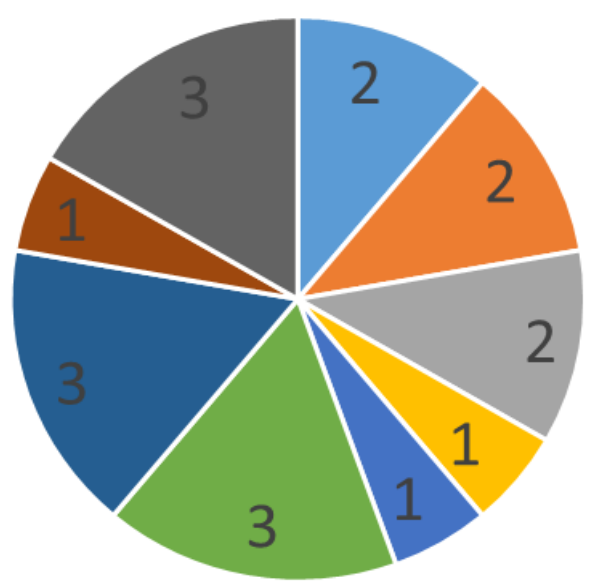

- Cardiotopônimos

- Cromotopônimos

- Dimensiotopônimos

- Fitotopônimo

- Geomorfotopônimo

- Hidrotopônimo

- Litotopônimo

- Morfotopônimo

- Zootopônimo

Gráfico 1: Hidrônimos classificados quanto à natureza física 


\section{NATUREZA ANTROPOCULTURAL}

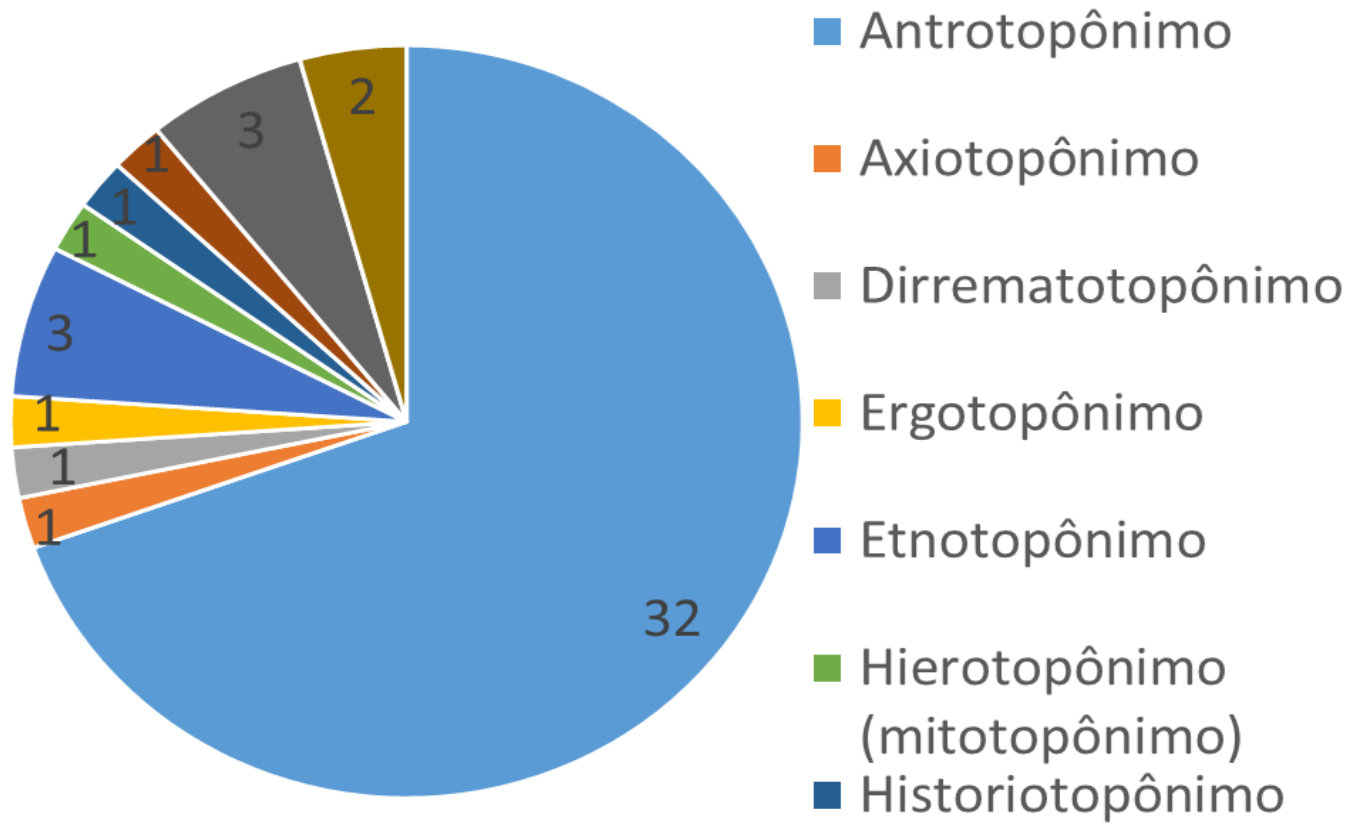

Gráfico 2: Hidrônimos classificados quanto à natureza antropocultural.

Em comparação à riqueza taxionômica dos 66 hidrônimos, observou-se não ser tão rica a tipologia dos acidentes (somente: córrego, ribeirão, cabeceira, rio, lagoa e cachoeira).

Foram 17 topônimos de natureza física, 46 de natureza antropocultural e três sem classificação. Dentre os 46, 32 são antrotopônimos, ou seja, metade de todos os hidrônimos são nomes de pessoas, sendo 30 nomes de mulheres. Essa nomeação provavelmente não é por homenagem a pessoas determinadas, se consideramos que a nomeação das ruas de Sinop recentemente é que começou a ter esta característica. Dick afirma que:

"Diferentemente, dos nomes de ruas, os hidrotopônimos não se modificam, ou seja, não são rebatizados, o que constata que o nome incorpora em si, no seu conceito, significado ou no pensamento individual, as próprias características daquilo que designa" (Dick, 2004, pág. 124)

Temmerman (2000) reafirma o caráter experiencial do ato de denominar:

"Sociocognitive Terminology considers our knowledge about the world of Science and technology as experiencial (Lakoff 1987). Much of what we know and understand about the world is 
embodied (Johnson 1987), is the result of our sensory perceptions. It shoul be added that the other part is the result of our reasoning, which is interactive with the input via on the one hand sensory perception and on the other hand the transfer of other language users' idea which we take in via discourse (written and spoken) for which language is the medium." (TEMMERMAN, 2000, pág. 61).

É possível dizer que a significativa presença de antropônimos femininos desvele $\mathrm{o}$ modelo de metáfora imagética entre mulher $\mathrm{e}$ córrego/cabeceira/cachoeira/ lagoa/ribeirão. A riqueza da natureza hídrica amazônica, abstrata e "mágica", é concretizada em um domínio próximo e familiar - seja pela sinuosidade das formas, pela abundância, pelo movimento constante ou pela riqueza de valores, entre outras possíveis imagens socioculturalmente armazenadas. Trata-se da experiência humana que, ao nomear elementos CONCRETOS da natureza, recategorizou a natureza acionando o modelo cognitivo idealizado pela representação de PESSOA DO SEXO FEMININO. A metáfora presente na nomeação dos hidrônimos sinopenses é concretizada no poema de tradição indiana, apresentado por Lakoff e traduzido livremente por Matos (1993, p. 229 apud MATOS, 2010). No poema, estão relacionados dois pares de domínios conceituais: (a) a imagem do caminhar lento de uma mulher com a da correnteza do rio e (b) a imagem do brilho de um cardume com o do cinto que adorna a mulher:

\author{
Agora a mulher-rio \\ Cingida por peixes prateados \\ Move-se sem pressa como uma mulher apaixonada \\ Ao amanhecer depois de uma noite de amor com seu amante
}

\title{
Referências
}

CARTA TOPOGRÁFICA DE SINOP, folha SD.21-Z-C-VI. MI 1814. Brasília: Ministério do Exército, Diretoria de Serviço Geográfico (DSG). 1976. 1 carta, color. Escala $1: 100.000$.

DICK, Maria Vicentina de Paula do Amaral. Fundamentos teóricos da Toponímia. Estudo de caso: o Projeto ATEMIG - Atlas Toponímico do Estado de Minas Gerais (variante regional do Atlas Toponímico do Brasil). SEABRA, Maria Cândida Costa de. (Org.) O Léxico em Estudo. Belo Horizonte: Faculdade de Letras da UFMG, 2006. P. 91-118.

DICK, Maria Vicentina de Paula do Amaral.. Rede de Conhecimento e Campo Lexical: Hidrônimos e Hidrotopônimos na Onomástica Brasileira. In: As ciências do léxico: Lexicologia, Lexicografia, Terminologia. Campo Grande: UFMS. 2004. p. 121-130. 
DICK, Maria Vicentina de Paula do Amaral.. Motivação toponímica. Princípios teóricos e modelos taxionômicos(A). São Paulo, 1980. 351 f. Tese (Doutorado em Linguística) - Faculdade de Filosofia, Letras e Ciências Humanas, Universidade de São Paulo.

GUIRAUD, Pierre. A Semântica. São Paulo/Rio de Janeiro: Difel, 1972.

LAKOFF, George y JOHNSON, Mark. Metáforas de la vida cotidiana. 8ª ed. Trad.de Carmen González Marín. Madrid: Ediciones Cátedra, 2009.

LAKOFF, G. Women, fire, and dangerous things: what categories reveal about the mind. Chicago; London: The University of Chicago Press, 1987.

FERRARI, Lilian. Introdução à Linguística Cognitiva. São Paulo: Contexto, 2011.

MATOS, Lúcia Helena Lopes de. Um modelo de construção da autonomia interpretativa. 2010. Disponível em https://ufsj.edu.br/portal2repositorio/File/vertentes/v.\%2019\%20n.\%201/Lucia Helena.pdf. Último acesso em 30 de abril de 2018.

SILVA, Fernando Moreno da e SILVA, Anderson Camilo Machado da. A toponímia da região paranaense do norte pioneiro. Revista (Com) Textos Linguísticos. v. 10, n. $\underline{17}$ (2016). Disponível em http://www.periodicos.ufes.br/contextoslinguisticos/article/view/14792/10809 $>$, último acesso em 28 abril de 2018.

SILVA, Augusto Soares da. A Linguística Cognitiva - uma breve introdução a um novo paradigma em linguística. 1997. Disponível em http://www.inf.unioeste.br/ jorge/MESTRADOS/LETRAS\%20\%20MECANISMOS\%20D0\%20FUNCIONAMENTO\%20DA\%20LINGUAGEM\%20\%20PROCESSAMENTO\%20DA\%20LINGUAGEM\%20NATURAL/ARTIGOS\%20INT ERESSANTES/Lingu\%EDstica\%20Cognitiva.pdf. Último acesso em 2 jan. 2019.

Anexo 1 : Carta Topográfica.

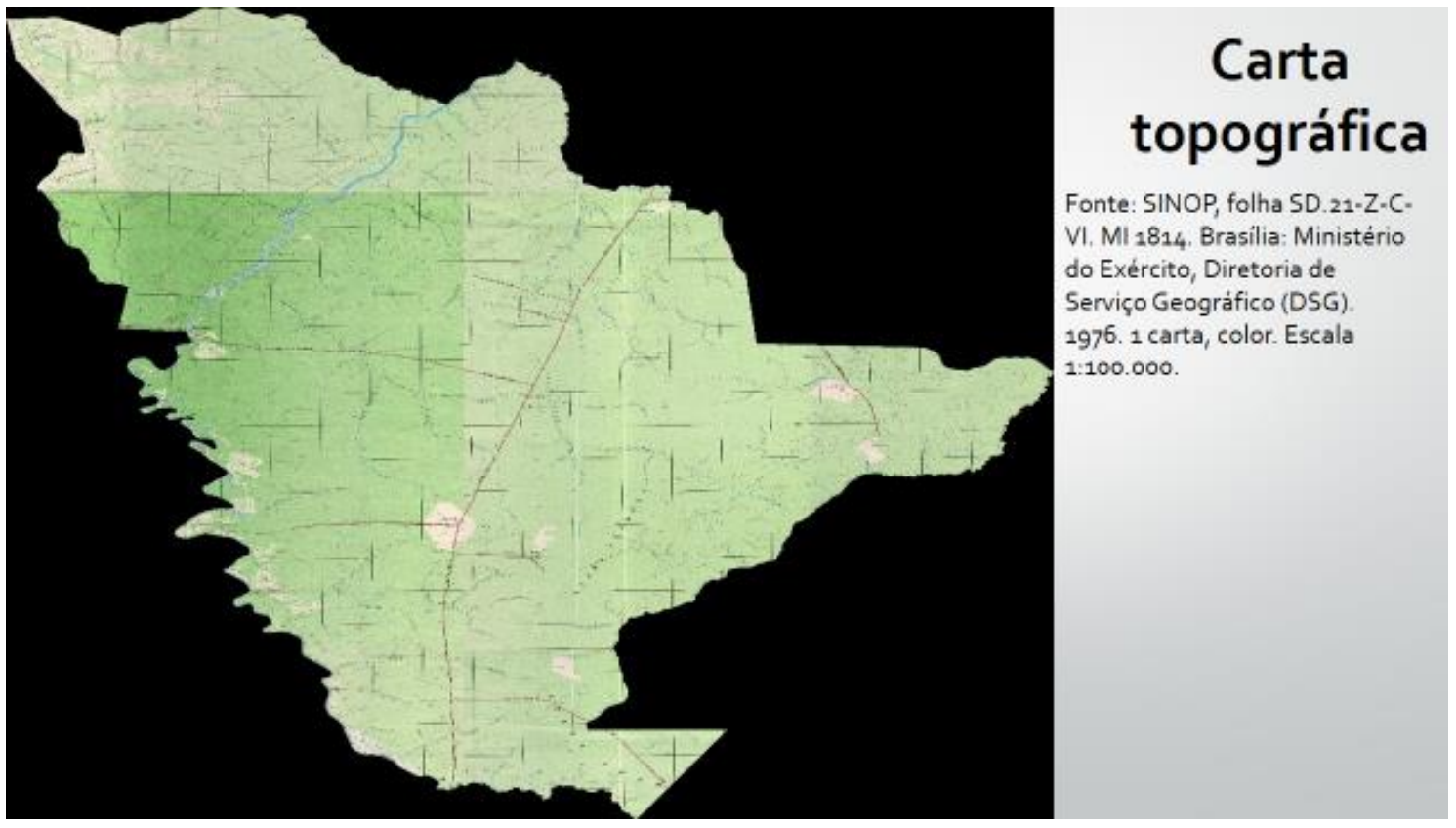

